\title{
Formation of Highly Ordered Self-Assembled Monolayers of Alkynes on Aul111) Substrate
}

\section{Citation}

Zaba, Tomasz, Agnieszka Noworolska, Carleen Morris Bowers, Benjamin Breiten, George M. Whitesides, and Piotr Cyganik. 2014. Formation of Highly Ordered Self-Assembled Monolayers of Alkynes on Au(111) Substrate. Journal of the American Chemical Society 136, no. 34: 1191811921. doi:10.1021/ja506647p.

\section{Published Version}

doi:10.1021/ja506647p

\section{Permanent link}

http://nrs.harvard.edu/urn-3:HUL.InstRepos:33490483

\section{Terms of Use}

This article was downloaded from Harvard University's DASH repository, and is made available under the terms and conditions applicable to Open Access Policy Articles, as set forth at http:// nrs.harvard.edu/urn-3:HUL.InstRepos:dash.current.terms-of-use\#OAP

\section{Share Your Story}

The Harvard community has made this article openly available.

Please share how this access benefits you. Submit a story.

\section{Accessibility}


Thin organic films based on self-assembled monolayers $(\mathrm{SAMs})^{1}$ are ubiquitous in surface science. The reaction of organic thiols (RSH) with group $\mathrm{Ib}$ metals $(\mathrm{Au}$ and $\mathrm{Ag}$ ) to generate SAMs with composition $\mathrm{Au} / \mathrm{AgSR}$ is the reaction most commonly used to prepare SAMs, ${ }^{1}$ although reactions that generate organosilanes on silicon ${ }^{2}(\mathrm{SiR})$ and organic carboxylates on silver ${ }^{3}$ $\left(\mathrm{AgO}_{2} \mathrm{CR}\right)$ have attractive properties, and a number of other precursors have been surveyed. There have also been scattered descriptions of SAMs formed on gold from solutions of alkynes ${ }^{4}$ $\left(\mathrm{HC} \equiv \mathrm{C}\left(\mathrm{CH}_{2}\right)_{\mathrm{n}} \mathrm{CH}_{3}, \mathrm{n}=3,5,7,9,11\right.$, and 13), ethynylbenzene ${ }^{5}$ ( $\left.\mathrm{HC} \equiv \mathrm{CC}_{6} \mathrm{H}_{5}\right)$ or $n$-alkylmercury(II) tosylates ${ }^{6}\left(\mathrm{CH}_{3}\left(\mathrm{CH}_{2}\right)_{\mathrm{n}} \mathrm{HgOTs}\right.$, $\mathrm{n}=4$ and 18) on $\mathrm{Au}(111)$. Although the potential interest of SAMs having Metal $-\mathrm{C} \equiv \mathrm{CR}$ bonds is high, since they offer a new type of metal-organic bond, most of these studies have used preparations analogous to those employed with $n$-alkanethiols, and have generated SAMs that have not seemed to be highly ordered, and are thus, perhaps, unsuitable for detailed studies of the physical chemistry of the surface. In particular, there are no procedures that describe the formation of SAMs that are highly ordered in two dimensions - a key requirement for high-quality surface science. The most recent analyses of $n$-alkyl-based SAMs on $\mathrm{Au}(111)$ indicate a "liquid-like" structure of the monolayer, ${ }^{6}$ and XPS analyses of SAMs formed from alkynes ${ }^{4,5}$ suggest that these

\begin{abstract}
Self-assembled monolayers (SAMs), prepared by reaction of terminal $\mathrm{n}$-alkynes $\left(\mathrm{HC} \equiv \mathrm{C}\left(\mathrm{CH}_{2}\right)_{\mathrm{n}} \mathrm{CH}_{3}, \mathrm{n}=5,7,9\right.$, tunneling microscopy (STM), infra-red reflection absorption and contact angles of water. In contrast to previous spectroscopic studies of this type of SAMs, these combined microscopic an SAMs having packing densities and molecular chain orientations very similar to those of alkanethiolates on $\mathrm{Au}(111)$. Physical
properties - hydrophobicity, high surface order, and packing density - also suggest that SAMs of alkynes are similar to SAMs of alkanethiols. The formation of high-quality SAMs from al-
kynes requires careful preparation and manipulation of reactants in an oxygen-free environment: trace quantities of oxygen lead to oxidized contaminants and disordered surface films. The oxida-
tion process occurs during formation of the SAM; via oxidation of the $-\mathrm{C} \equiv \mathrm{C}-$ group (most likely catalyzed by the gold substrate in the presence of $\mathrm{O}_{2}$ ).
\end{abstract}

SAMs are sensitive to oxidation at an undefined point in their formation; that is, oxidation occurs either during or after SAM formation (for example, by reaction of the $\mathrm{AuC} \equiv \mathrm{CR}$ bond with $\mathrm{O}_{2}$ ). Contact angle analyses of increasing lengths of alkynes $\left(\mathrm{HC} \equiv \mathrm{C}\left(\mathrm{CH}_{2}\right)_{n} \mathrm{CH}_{3}, \mathrm{n}=5,7,9\right.$ and 11) also suggest ${ }^{4}$ that the quality of these SAMs is lower than those based on $n$-alkanethiols.

Although SAMs have enabled studies of wetting, ${ }^{7,8}$ adhesion, ${ }^{9,10}$ and charge transport ${ }^{3,11-13}$ (inter alia), most of this work has focused on the terminal part of the SAM that is exposed to air, and there is relatively little work devoted to understanding the contribution of the anchoring groups of the SAM (as opposed to the terminal group, the thickness, or the electronic structure). In the current work, we characterize the SAMs formed by reactions of $n$-alkynes $\left(\mathrm{HC} \equiv \mathrm{C}\left(\mathrm{CH}_{2}\right)_{\mathrm{n}} \mathrm{CH}_{3}, \mathrm{n}=5,7,9\right.$ and 11) with $\mathrm{Au}(111)$. We believe that the $\mathrm{AuC} \equiv \mathrm{CR}$ group is particularly interesting as the basis for SAMs on Au for two reasons: i) the acetylene group connects with gold atoms on the surface by a strong $\sigma$-bond; ${ }^{14}$ ii) the orbital structure of the acetylene group, and the existence of a variety of stable organometallic compounds containing the $\mathrm{AuC} \equiv \mathrm{CR}$ group, suggests that the interface between the metal, $\mathrm{Au}$, and the saturated organic component of the SAM $(\mathrm{R}=$ $\left.\left(\mathrm{CH}_{2}\right)_{\mathrm{n}} \mathrm{CH}_{3}\right)$, might be especially informative in studies in which the interface connecting the SAM to the metallic substrate might contribute to its properties.

The objective of this work was to address the question of the order of $n$-alkyne-derived SAMs on gold through a combination of microscopic, spectroscopic and contact angle measurements. Our results show that the disorder and mixed organic functionality implied by previous work ${ }^{4-6}$ are artefacts reflecting oxidation of the terminal acetylene by oxygen in solution during formation of the SAM (perhaps in a reaction catalyzed by gold), ${ }^{15}$ and that using appropriate experimental conditions (e.g., rigorous exclusion of oxygen; a slightly elevated temperature of $60^{\circ} \mathrm{C}$ during formation of the SAM) results in well-organized SAMs of alkynes that have qualities similar to that of alkanethiols on $\mathrm{Au}(111)$. These studies thus establish that SAMs of the surface composition $\mathrm{AuC} \equiv \mathrm{CR}$ provide a new type of SAM for use in physical- and physical-organic studies having an interface to gold $(\mathrm{AuC} \equiv \mathrm{CR})$, and are complementary to the well-understood SAMs of alkanethiols (AuSR).

SAMs of alkynes were prepared on gold by submerging freshly evaporated $\mathrm{Au}(111)$ substrates in a $1 \mathrm{mM}$ ethanolic solution of $n$ alkyne $\left(\mathrm{HC} \equiv \mathrm{C}\left(\mathrm{CH}_{2}\right)_{\mathrm{n}} \mathrm{CH}_{3}, \mathrm{n}=5,7,9\right.$, and 11) for 15 hours at $60^{\circ} \mathrm{C}$. Importantly, the preparation of the SAMs was performed in 

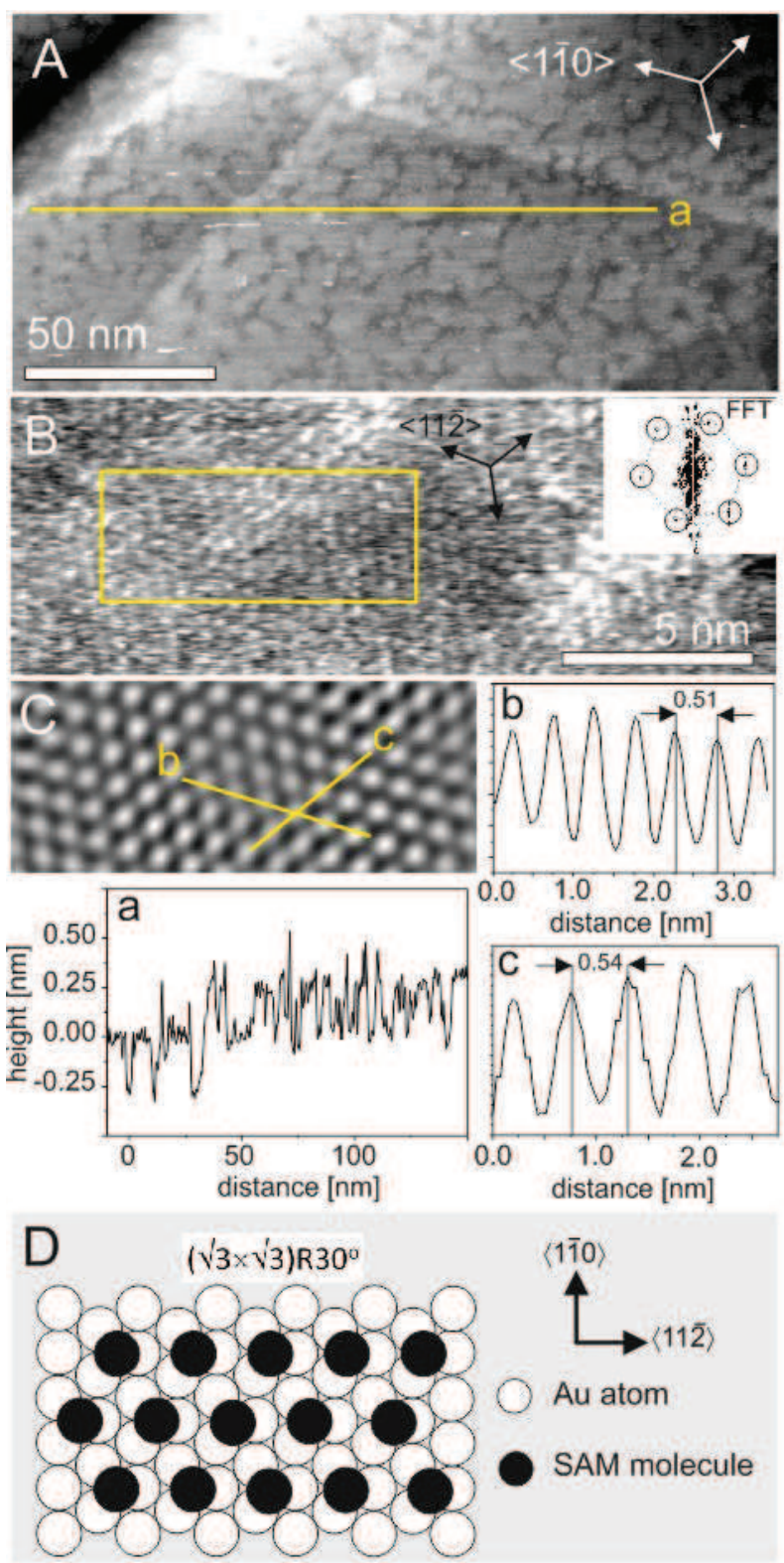

Figure 1. In (a-c) STM data for decyne/Au(111) SAMs. Panels assigned as A, B and C show cross-sections A, B and C indicated in (a-c), respectively. The inset in (b) shows FFT spectrum of image (b) with indicated six-fold symmetry pattern. Yellow rectangle in (b) marks an area which corresponds to the image shown in (c) obtained after FFT filtering of (b). In (d) scheme of decyne adsorption in the $(\sqrt{3} \times \sqrt{3}) \mathrm{R} 30^{\circ}$ structure with arbitrary taken adsorption seats.

an oxygen-free environment to avoid oxidation of the acetylene group. The supporting information (SI) provides a more detailed description of the experimental procedure, as well as additional details of measurements.

Figure 1 summarizes the results obtained by scanning tunneling microscopy (STM) for decyne $(\mathrm{n}=7)$ chemisorbed on $\mathrm{Au}(111)$. Analysis on a larger scale (Figure 1a) shows formation of depressions on the substrate with depths compatible with substrate lattice steps due to a single atomic layer of gold (as indicated by the respective cross-section, marked by $A$ ). Such depressions are also characteristic of formation of both thiol- ${ }^{1}$ and selenol- ${ }^{16}$ based SAMs on $\mathrm{Au}(111)$, and probably result mainly from lifting the $\mathrm{Au}(111)$ herringbone reconstruction upon chemisorption of these

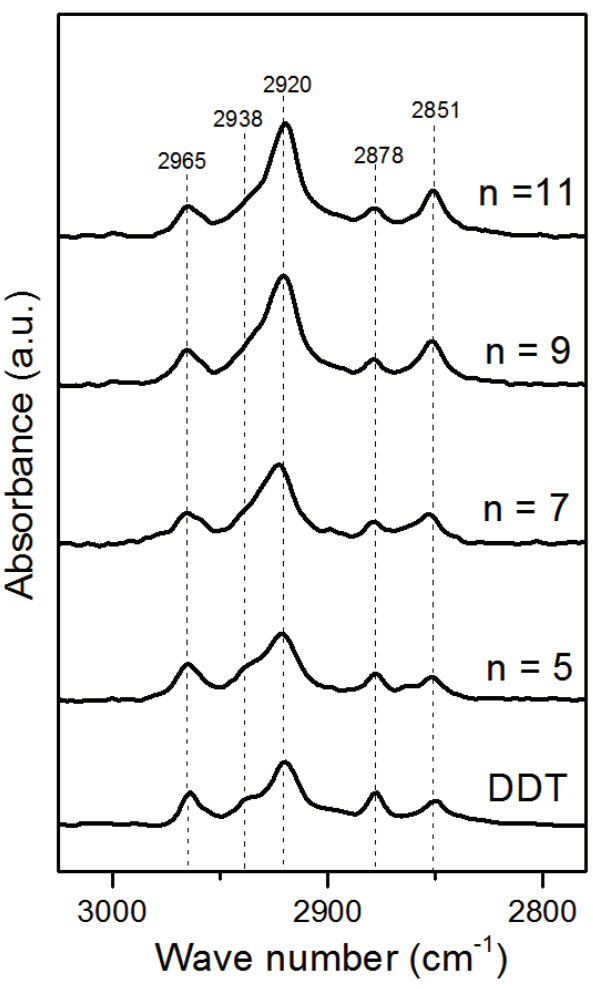

Figure 2. Overview of IRRAS data for $\mathrm{n}=5,7,9$ and 11 alkynes on $\mathrm{Au}(111)$ together with the corresponding $\mathrm{DDT} / \mathrm{Au}(111)$ in the characteristic $\mathrm{C}-\mathrm{H}$ stretching range.

molecules. ${ }^{17}$ The detection of similar features for alkynes suggests the formation of densely packed chemisorbed structures on $\mathrm{Au}(111)$.

This inference of a dense monolayer is confirmed by highresolution STM, accompanied by Fourier analysis (using Fast Fourier Transform, FFT), which shows a hexagonal lattice. The data obtained after FFT filtering (Figure 1c) suggest a hexagonal structure with a period of ca. $5 \AA$, as indicated by the line scans along the axes. The structure inferred from this analysis (shown schematically in Figure 1d) is consistent with the $(\sqrt{3} \times \sqrt{3}) \mathrm{R} 30^{\circ}$ lattice (which characterizes the structure formed by alkanethiols on $\mathrm{Au}(111)^{18}$ and leads to an area per molecule of $21.5 \AA^{2}$. While the quality of our data does not permit a more detailed description of the structure (as was possible for alkanethiols, which exhibit a $\mathrm{c}(4 \times 2)$ superlattice $),{ }^{18}$ it certainly shows that alkynes on $\mathrm{Au}(111)$ form well-ordered structures with packing densities similar to those of alkanethiols (area per molecule 21.5 $\AA^{2}$ ).

To characterize the orientational order of alkyne-based SAMs further, we used infra-red reflection absorption spectroscopy (IRRAS). IRRAS measurements of the SAMs - formed by reaction of octyne $(n=5)$, decyne $(n=7)$, dodecyne $(n=9)$ and tetradecyne $(\mathrm{n}=11)$ with $\mathrm{Au}(111)$ - showed vibrational bands in the $\mathrm{C}-\mathrm{H}$ stretching range at $2965 \mathrm{~cm}^{-1}\left(\mathrm{v}_{\mathrm{a}} \mathrm{CH}_{3}\right), 2938 \mathrm{~cm}^{-1}\left(\mathrm{v}_{\mathrm{s}} \mathrm{CH}_{3}\right.$, FR $), 2920 \mathrm{~cm}^{-1}\left(v_{\mathrm{a}} \mathrm{CH}_{2}\right), 2878 \mathrm{~cm}^{-1}\left(v_{\mathrm{s}} \mathrm{CH}_{3}, \mathrm{FR}\right)$, and $2851 \mathrm{~cm}^{-1}$ $\left(v_{\mathrm{s}} \mathrm{CH}_{2}\right)$ (Figure 2). For comparison, analogous IRRAS measurements were performed on SAMs of dodecanethiol (DDT) on $\mathrm{Au}(111)$. This comparison shows that the frequencies, relative intensities and the band width of the spectra for $\mathrm{AuC} \equiv \mathrm{CR}$ and AuSR are similar (for more details see Figure 1S in the SI). ${ }^{19}$ For the same orientation of $n$-alkynyl and alkanethiol on $\mathrm{Au}(111)$, however, we would expect the DDT $\left(\mathrm{n}_{\mathrm{CH} 2}=11\right)$ spectrum to be close to that of tetradecyne $\left(\mathrm{n}_{\mathrm{CH} 2}=11\right)$, which has a comparable aliphatic chain length $\left(\left(\mathrm{CH}_{2}\right)_{\mathrm{n}} \mathrm{CH}_{3}\right)$. Instead, the DDT spectrum intensity is similar to that of octyne $\left(\mathrm{n}_{\mathrm{CH} 2}=5\right)$. As a result of 


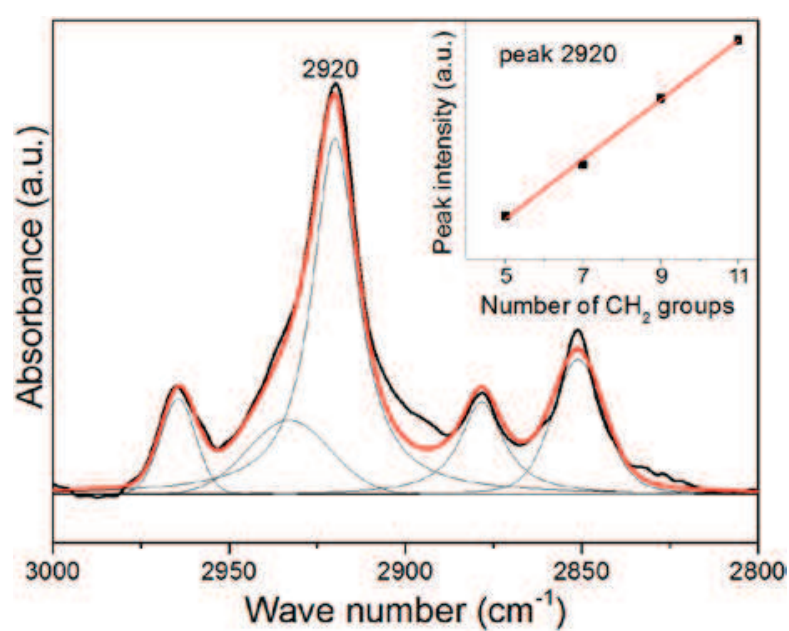

Figure 3. IRRAS data analysis for tetradecyne/Au(111) with fitting individual bands. The inset shows linear increase in 2920 $\mathrm{cm}^{-1}$ peak intensity as a function of the $\mathrm{CH}_{2}$ group number.

surface selection rules, IRRAS intensities are sensitive to the orientation of the molecules within the SAM (with respect to the metal substrate); the data in Figure 2 suggest slightly different twisting and/or tilting of the $\left(\mathrm{CH}_{2}\right)_{n} \mathrm{CH}_{3}$ chain for the $n$-alkynyl and alkanethiolate on $\mathrm{Au}(111)$. These differences are not surprising considering the different bonding geometries for each SAM. We also note that the observed differences in the IRRAS spectra for $n$-alkynyl and alkanethiol on $\mathrm{Au}(111)$ are much smaller than those reported previously ${ }^{19}$ for alkanethiolates on $\mathrm{Au}(111)$ and $\operatorname{Ag}(111)$, which have similar surfaces structures.

Figure 3 shows a more detailed analysis of the IRRAS spectra for tetradecyne, including a fitting for the $\mathrm{C}-\mathrm{H}$ stretching modes. The inset in Figure 3 shows that an increase in the length of the aliphatic chain (from $n=5$ up to $n=11$ ) correlates linearly with the intensity of the $\mathrm{CH}_{2}$-related symmetric $\left(2920 \mathrm{~cm}^{-1}\right)$ mode. This observation indicates that the conformation of $n$-alkynes on

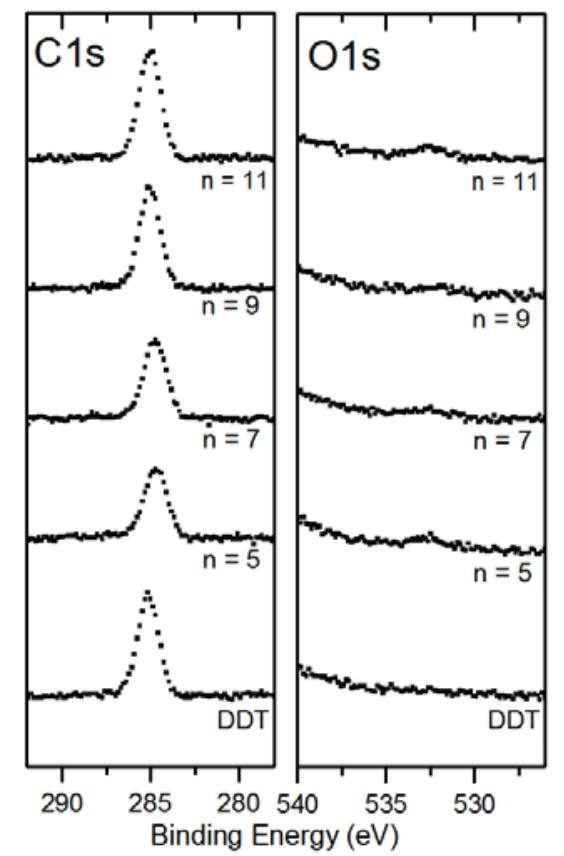

Figure 4. XPS $\mathrm{C} 1 \mathrm{~s}$ and $\mathrm{O} 1 \mathrm{~s}$ data for $\mathrm{n}=5,7,9$ and 11 alkynes on $\mathrm{Au}(111)$ together with the corresponding $\mathrm{DDT} / \mathrm{Au}(111)$.

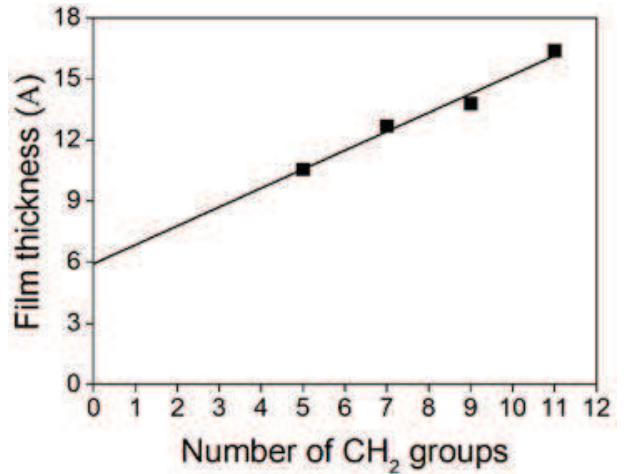

Figure 5. Film thickness calculated in number of methylene groups $\left(\left(\mathrm{CH}_{2}\right)_{\mathrm{n}}\right)$ from the XPS data (see text) for SAMs of $\mathrm{HC} \equiv \mathrm{C}\left(\mathrm{CH}_{2}\right)_{\mathrm{n}} \mathrm{CH}_{3},(\mathrm{n}=5,7,9$, and 11) on $\mathrm{Au}(111)$. The solid line indicates a linear fit.

$\mathrm{Au}(111)$ is preserved across the entire series of alkynes that we investigated; Nuzzo et al. reported a similar observation in earlier spectroscopic studies of alkanethiols on $\mathrm{Au} .{ }^{19}$ In contrast to our observations, recent PM-IRRAS experiments by Scholz et al. ${ }^{6}$ (based on analysis of the $\mathrm{C}-\mathrm{H}$ stretching range) performed for alkyl-based SAMs - $n$-butylmercury tosylate $\left(\mathrm{C}_{4} \mathrm{H}_{9} \mathrm{HgOTs}\right)$ and $n$-octadecylmercury tosylate $\left(\mathrm{C}_{18} \mathrm{H}_{37} \mathrm{HgOTs}\right)$ on golddemonstrated fundamental differences in the relative intensities and band broadening between these SAMs and analogous alkanethiols: that is, the $n$-alkyls had a liquid-like structure (in contrast to the crystalline structure observed for $n$-alkanethiols). In contrast, the IRRAS data presented in Figures 2 and 3 demonstrates that it is possible to form alkynes that have order similar to that of alkanethiols on $\mathrm{Au}(111)$.

Figure 4 shows X-ray photoelectron spectroscopy (XPS) analysis of the alkyne-based SAMs. In contrast to previously reported XPS data for increasing lengths of alkynes $\left(\mathrm{HC} \equiv \mathrm{C}\left(\mathrm{CH}_{2}\right)_{n} \mathrm{CH}_{3}, \mathrm{n}=\right.$ $5,7,9$, and 11), ${ }^{4}$ the $\mathrm{C} 1 \mathrm{~s}$ signal in Figure 4 shows a single symmetric peak at $285 \mathrm{eV}$, with no additional higher energy components (e.g., peaks at $287 \mathrm{eV}, 289 \mathrm{eV}$ ). The $\mathrm{C} 1$ s spectra are also consistent with the corresponding data obtained for DDT (Figure 4), as well as other literature data ${ }^{20}$ for un-oxidized alkanethiols on $\mathrm{Au}(111)$. We calculated the film thickness using the $\mathrm{C} 1 \mathrm{~s} / \mathrm{Au} 4 \mathrm{f}$ intensity ratios (assuming an exponential attenuation of the photoelectron signal ${ }^{21}$ and using attenuation lengths reported earlier). ${ }^{22}$ The calculated values (summarized in Figure 5) show a linear increase in thickness as a result of an increase in the length of the chain (from $n=5$ to $n=11$ ). Importantly, the XPS data are consistent with the IRRAS data shown in Figure 3; they indicate a linear increase in the IR signal with an increasing number of methylene units $\left(\mathrm{CH}_{2}\right)$. Moreover, using the linear relation obtained from our XPS measurements data, we can extrapolate the thickness of the film for $n=0$ to a value of $5.9 \AA$; this value corresponds to the length expected for a $-\mathrm{C} \equiv \mathrm{CCH}_{3}$ fragment. This extrapolation is also consistent with the ca. $5.6 \AA$ dimensions of an upright configuration of the $-\mathrm{C} \equiv \mathrm{CCH}_{3}$ molecule on $\mathrm{Au}(111)$, on the basis of the bonds lengths provided by previous $\mathrm{DFT}^{23}$ calculations. Thus, the estimation of thickness using XPS is consistent with SAMs of $\mathrm{HC} \equiv \mathrm{C}\left(\mathrm{CH}_{2}\right)_{\mathrm{n}} \mathrm{CH}_{3}$ on $\mathrm{Au}(111)$ having the $-\mathrm{C} \equiv \mathrm{C}-$ group perpendicular to the surface. ${ }^{14}$

Previously reported XPS data for SAMs derived from ethynylbenzene $\left(\mathrm{HC} \equiv \mathrm{CC}_{6} \mathrm{H}_{5}\right)$ on gold ${ }^{5}$ suggested that the SAM contained oxidized components, as is inferred from both a significant $\mathrm{O} 1 \mathrm{~s}$ signal and higher-energy contributors to the $\mathrm{C} 1 \mathrm{~s}$ peak (e.g., peaks at $287 \mathrm{eV}, 289 \mathrm{eV}$ ). In contrast, data shown in Figure 4 show virtually no O1s signal for all SAMs analyzed, which were prepared carefully in an oxygen-free environment (the SI details the procedure). The oxidation of alkynes is indeed clearly visible for samples that were exposed to oxygen (ambient condi- 


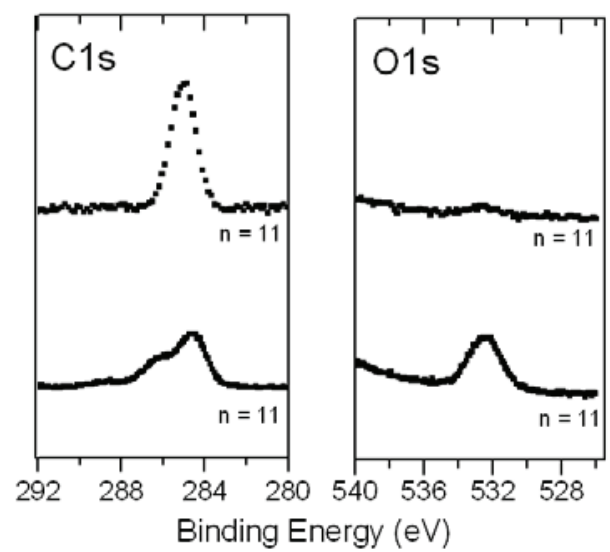

Figure 6. XPS region scans (C1s and O1s) for SAMs of $\mathrm{HC} \equiv \mathrm{C}\left(\mathrm{CH}_{2}\right)_{11} \mathrm{CH}_{3}$ on $\mathrm{Au}(111)$ prepared in an oxygen-free atmosphere (upper spectra) and an oxygen-containing atmosphere (lower spectra).

tions) during preparation of the SAMs (see Figure 6). In the XPS data (Figure 6), an intense O1s signal in this case is associated with significant changes in the $\mathrm{Cls}$ peak, and the appearance of higher energy components $(289 \mathrm{eV}, 287 \mathrm{eV})$ which cause significant asymmetry and broadening of the $\mathrm{C} 1 \mathrm{~s}$ peak, and are indicative of the oxidation of the $-\mathrm{C} \equiv \mathrm{C}-$ group as reported in ref. 5. Our data demonstrate that the oxidation of alkynes does not involve the $\mathrm{C}-\mathrm{Au}(111)$ bond formation (as had been suggested previous$\left.1 y^{5}\right)$, but instead involves oxidation of the alkynes in solution during formation of the SAM.

The interfacial free energy of $n$-alkyl SAMs on $\mathrm{Au}(111)$ was investigated using measurements of advancing contact angles of water $\left(\Theta_{\mathrm{H} 2 \mathrm{O}}^{\mathrm{a}}\right)$. The data (see Table 1 in the SI file) are in a range $\left(\Theta^{\mathrm{a}}{ }_{\mathrm{H} 2 \mathrm{O}}=111^{\circ}-115^{\circ}\right)$ that is consistent with the values measured here for DDT/Au(111), as well as literature data ${ }^{24}$ for SAMs of alkanethiols on $\mathrm{Au}(111)$. The values of $\Theta_{\mathrm{H} 2 \mathrm{O}}^{\mathrm{a}}$ presented here are significantly higher than those reported previously $\left(89^{\circ}-98^{\circ}\right)$ for alkynes on $\mathrm{Au}(111),{ }^{4}$ and serve as additional evidence of a similar degree of order for SAMs of alkynes (prepared properly) and alkanethiols on $\mathrm{Au}(111)$.

In conclusion, our STM and IRRAS data show that alkynes on $\mathrm{Au}(111)$ form SAMs that have organization and structure similar to alkanethiols on $\mathrm{Au}(111)$. High surface ordering and packing density of alkynes is also consistent with high values of $\theta_{\mathrm{H} 20}^{\mathrm{a}}$. The XPS data show that the presence of oxygen marks contamination of alkyne-based SAMs through oxidation of the acetylene group. The oxidation of $-\mathrm{C} \equiv \mathrm{C}-$ (most likely catalyzed by the gold substrate in the presence of $\mathrm{O}_{2}$ ) can be monitored by the appearance of high energy components and a broadening and asymmetry in the C1s signal. Alkynes appear to be more sensitive to oxidation than alkanethiols during formation of the SAM, and require the formation to be carried out carefully in an oxygen-free atmosphere.

\section{ASSOCIATED CONTENT}

\section{Supporting Information}

Experimental details are available free of charge via the Internet at http://pubs.acs.org

\section{AUTHOR INFORMATION}

\section{Corresponding Author}

piotr.cyganik@uj.edu.pl,
Notes

The authors declare no competing financial interests.

\section{ACKNOWLEDGMENT}

The authors would like to thank Prof. Marek Szymonski for providing access to the STM microscope at the Department of Physics of Nanostructures and Nanotechnology at the Jagiellonian University. This work was supported financially by the National Science Centre Poland (grant DEC-2013/10/E/ST5/00060). The XPS equipment was purchased with the financial support of the European Regional Development Fund (grant POIG.02.02.00-12023/08). The work at Harvard University was supported by a subcontract from Northwestern University from the United States Department of Energy (DOE, DE-SC0000989).

\section{REFERENCES}

(1) Love, J. C.; Estroff, L. A.; Kriebel, J. K.; Nuzzo, R G.; Whitesides, G. M. Chem. Rev. 2005, 105, 1103.

(2) Li, Y.; Calder, S.; Yaffe, O.; Cahen, D.; Haick, H.; Kronik, L.; Zuilhof, H. Langmuir 2012, 28, 9920.

(3) Liao, H. C.; Yoon, H. J.; Bowers, C. M.; Simeone, F. C.; Whitesides, G. M. Angew. Chem. Int. Ed. 2014, 53, 3889.

(4) Zhang, S.; Chandra, K. L.; Gorman, C. B. J. Am Chem. Soc. 2007, 129, 4876 .

(5) McDonagh, A. M.; Zareie, H. M.; Ford, M. J.; Barton, C. S.; Ginic-Markovic, M.; Matisons, J. G. J. Am. Chem. Soc. 2007, 129, 3533.

(6) Scholz, F.; Kaletova, E.; Stensrud, E. S.; Ford, W. E.; Kohutova, A.; Mucha, M.; Stibor, I.; Michl, J.; Wrochem, F. J. Phys. Chem. Lett. 2013, 4, 2624-2629.

(7) Drelich, J.; Wilbur, J. L.; Miller, J. D.; Whitesides, G. M. Langmuir 1996, 12, 1913.

(8) Hao, Y. J.; Soolaman, D. M.; Yu, H. Z. J. Phys. Chem. C 2013, 117, 7736 .

(9) Vezenov, D. V.; Zhuk, A. V.; Whitesides, G. M.; Lieber, C. M. J. Am. Chem. Soc. 2002, 124, 10578.

(10) Khan, M. N.; Tjong, V.; Chilkoti, A.; Zharnikov, M. Angew. Chem. Int. Ed. 2012, 51, 10303.

(11) Holmlin, R. E.; Haag, R.; Chabinyc, M. L.; Ismagilov, R. F.; Cohen, A. E.; Terfort, A.; Rampi, M. A.; Whitesides, G. M. J. Am. Chem. Soc. 2001, 123, 5075 .

(12) Venkataraman, L.; Klare, J. E.; Nuckolls, C.; Hybertsen, M. S.; Steigerwald, M. L. Nature 2006, 442, 904.

21,4303 .

(13) McCreery, R. L.; Bergren, A. J. Adv. Mater. 2009,

(14) Maity, P.; Takano, S.; Yamazoe, S.; Wakabayashi, T.; Tskuda, T. J. Am. Chem. Soc. 2013, 135, 9450.

(15) Tkatchouk, E.; Goddard, W. A.; Toste, D.; Brenzovich, W. E.; Lackner, A. D.; Shunatona, H. P.; Benitez, D. Abstr. Pap. Am. Chem. Soc. 2011, 241, 136.

(16) Romashov, L. V.; Ananikov, V. P. Chem. Eur. J.

2013, 19, 17640 .

(17) Poirier, G. E. Langmuir 1997, 13, 2019.

(18) Poirier, G. E. Chem. Rev. 1997, 97, 1117.

(19) Laibinis, P. E.; Whitesides, G. M.; Allara, D. L.; Tao, Y. T.; Parikh, A. N.; Nuzzo, R. G. J. Am. Chem. Soc. 1991, 113, 7152.

(20) Zharnikov, M.; Geyer, W.; Golzhauser, A.; Frey, S.; Grunze, M. Phys. Chem. Chem. Phys. 2000, 1,3163.

(21) Dannenberger, O.; Weiss, K.; Himmel, H. J.; Jager, B.; Buck, M.; Woll, C. Thin Solid Films 1997, 307, 183.

(22) Lamont, C. L. A.; Wilkes, J. Langmuir 1999, 15,

2037.

(23) Ford, M. J.; Hoft, R. C.; McDonagh, A. M. J. Phys. Chem. B 2005, 109, 20387.

(24) Bain, C. D.; Troughton, E. B.; Tao, Y. T.; Evall, J.; Whitesides, G. M.; Nuzzo, R. G. J. Am. Chem. Soc. 1989, 111, 321. 
1

2

3

4

5

6

7

8

9

10

11

12

13

14

15

16

17

18

19

20

21

22

23

24

25

26

27

28

29

30

31

32

33

34

35

36

37

38

39

40

41

42

43

44

45

46

47

48

49

50

51

52

53

54

55

56

57

58

59

60
TOC
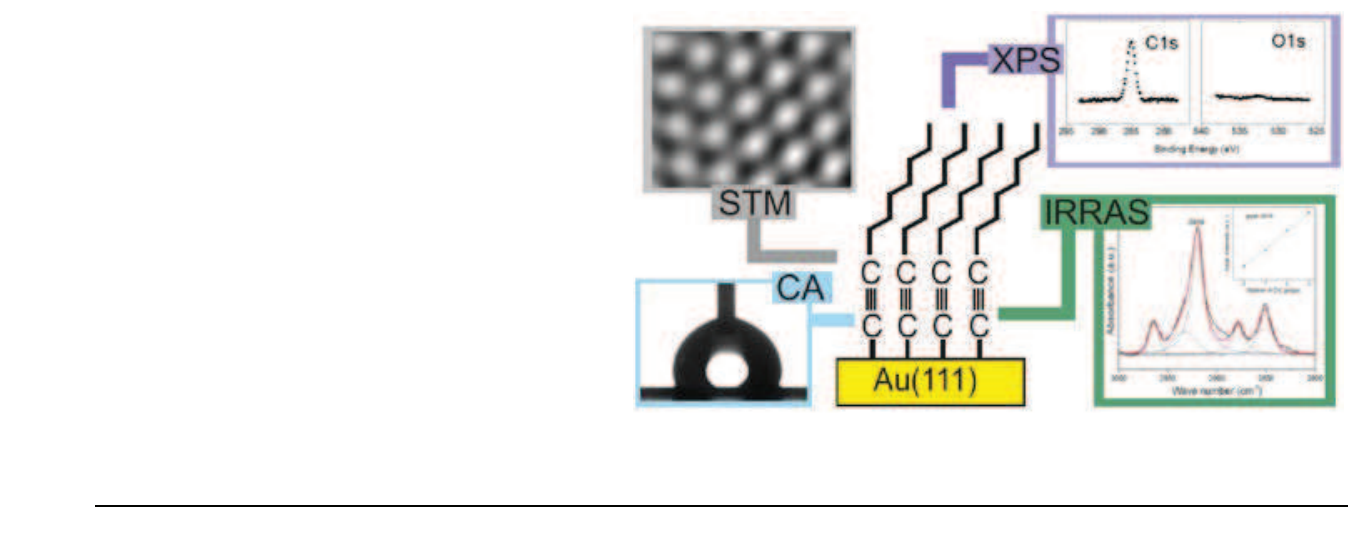